\title{
Brucellosis in a refugee who migrated from Syria to Germany and lessons learnt, 2016
}

R Grunow ${ }^{1}$, D Jacob ${ }^{1}$, S Klee ${ }^{1}$, D Schlembach ${ }^{2}$, S Jackowski-Dohrmann ${ }^{3}$, V Loenning-Baucke ${ }^{4}$, B Eberspächer ${ }^{5}$, S Swidsinski 5

1. Robert Koch Institute, Berlin, Germany

2. Vivantes Klinikum Neukölln, Geburtsmedizin, Berlin, Germany

3. Vivantes Klinikum Neukölln, Kinder und Jugendmedizin, Berlin, Germany

4. Charité Hospital, Campus Charité Mitte, Laboratory for Molecular Genetics, Polymicrobial Infections and Bacterial Biofilms, Berlin, Germany

5. Labor Berlin, Berlin, Germany

Correspondence: Roland Grunow (GrunowR@rki.de)

Grunow R, Jacob D, Klee S, Schlembach D, Jackowski-Dohrmann S, Loenning-Baucke V, Eberspächer B, Swidsinski S. Brucellosis in a refugee who migrated from Syria to Germany and lessons learnt, 2016. Euro Surveill. 2016;21(31):pii=30311. DOI: http://dx.doi.org/10.2807/1560-7917.ES.2016.21.31.30311

A teenage woman migrating from Syria arrived in May 2015 in Germany. She gave birth to a healthy child in early 2016, but became febrile shortly after delivery. Blood cultures revealed Brucella melitensis. In retrospect, she reported contact with sheep in Syria and recurrent pain in the hip joints over about five months before diagnosis of brucellosis. We discuss consequences for adequate treatment of mother and child as well as for clinical and laboratory management.

As brucellosis is rare in many European countries and because there is even less experience with brucellosis in association with pregnancy, we here publish a case of a young pregnant woman who had migrated from Syria to Germany and was diagnosed with brucellosis directly after delivery of her child, and illustrate some lessons learnt.

\section{Case report}

A teenage female refugee from Syria delivered a fullterm baby (birthweight 3,185 g) with vacuum extraction in Germany. Because of intrapartum asphyxia, mother and child were hospitalised in a special care unit. The child recovered without further complications. The mother developed a fever of $39^{\circ} \mathrm{C}$ on day 1 after delivery. Investigation of the mother's blood revealed normal ranges of leukocytes, a slightly decreased haemoglobin level and an elevated concentration of C-reactive protein (CRP) at $38.0 \mathrm{mg} / \mathrm{mL}$ (normal<5.0 $\mathrm{mg} / \mathrm{L}$ ). She was treated for three days with intravenous ampicillin sulbactam $3 \mathrm{~g}$ three times daily and metronidazole $500 \mathrm{mg}$ twice daily. The patient was in good clinical condition and discharged from the hospital on day 4 with oral sultamicillin $375 \mathrm{mg}$ and metronidazole $400 \mathrm{mg}$ twice daily.

Two sets of blood cultures (BD Bactec Fx blood culture system) were taken during pyrexia. One anaerobic culture revealed a positive signal after $47 \mathrm{~h}$ incubation that was identified as Fusobacterium nucleatum. The aerobic blood culture revealed growth after $117 \mathrm{~h}$ and Gram staining showed faintly stained small Gramnegative coccobacilli (Figure 1). Small non-haemolytic colonies appeared on Columbia blood agar after 48 hours incubation at $36^{\circ} \mathrm{C}$ in air with $5 \% \mathrm{CO} 2$ enrichment (Figure 2) and were oxidase-positive. Using matrix-assisted laser desorption ionisation time of flight (MALDI-TOF) mass spectrometry (MS) (MALDITOF MS, Vitek MS Plus System bioMérieux, research use only (RUO) SARAMIS database), Brucella spp. was identified and confirmed as Brucella melitensis one day later when tested by real-time PCR in a reference laboratory using an accredited in-house assay.

Because of the results of the aerobic blood culture, the mother and child were immediately contacted and examined on day 11 after delivery. The mother reported that she was a sheepherder in Syria before arriving in Germany nine months previously and that she had suffered from recurrent hip pain for about five months before diagnosis of brucellosis. The serum sample was tested in parallel with two ELISAs revealing a high titre of 1:16,000 (normal:<1:500; Virion-Serion $\mathrm{GmbH}$, Würzburg, Germany) of Brucella-specific antibodies, with IgG of $29.1 \mathrm{U}$ and IgM of $24.3 \mathrm{U}$ (cut-off: $10 \mathrm{U}$; Novagnost Brucella IgG and IgM ELISA, Siemens Healthcare Diagnostics, Germany). Samples of mother's milk were not available for laboratory investigation. The patient was advised to start antibiotic therapy with doxycycline $100 \mathrm{mg}$ twice daily and rifampicin 900 mg once daily for 12 weeks and to stop breastfeeding.

The examination of the baby by the paediatrician revealed no relevant clinical or laboratory abnormalities. The blood culture set up day 11 after birth 


\section{FIGURE 1}

Gram staining of bacterial culture showing faintly stained small Gram-negative coccobacilli corresponding to Brucella spp., Germany, 2016

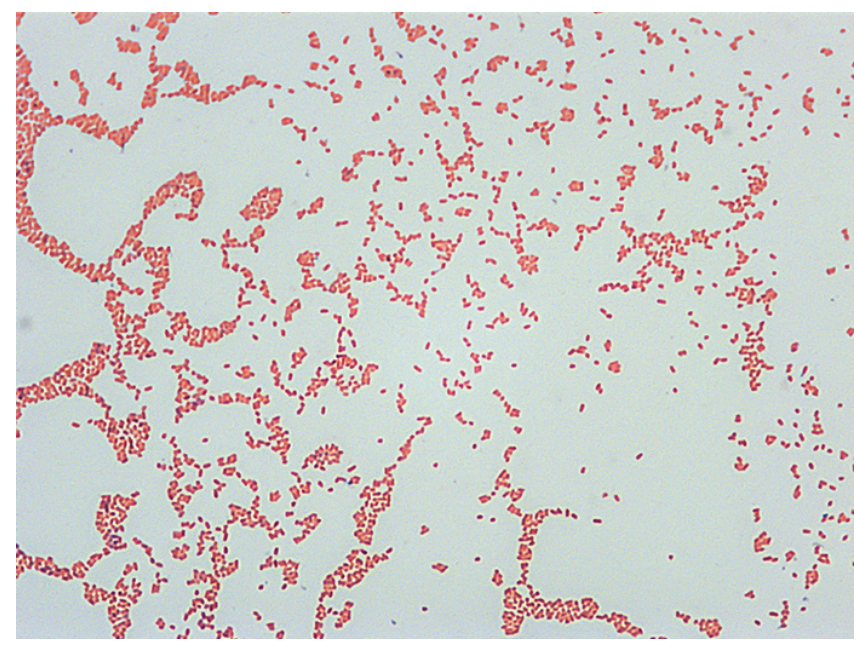

\section{FIGURE 2}

Bacteria isolated from blood culture forming small nonhaemolytic colonies on Columbia blood agar after 48 hours incubation at $36^{\circ} \mathrm{C}$ air with $5 \% \mathrm{CO} 2$ enrichment, Germany, 2016

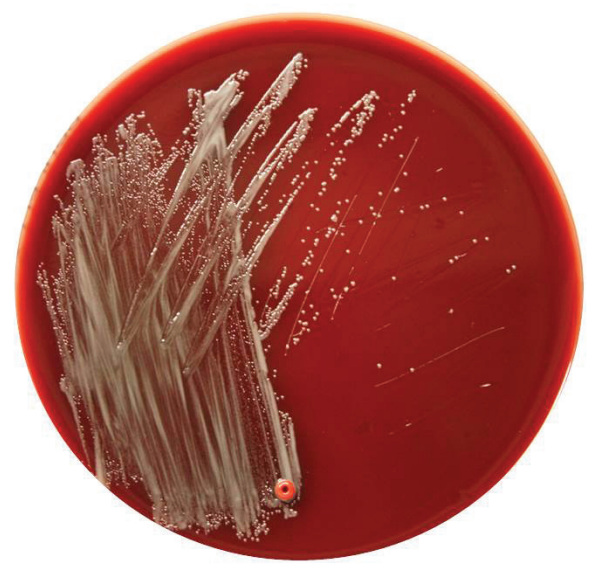

remained negative, the serum sample was positive only for Brucella-specific IgG antibodies (24.5 U).

In subsequent visits (four and seven weeks after delivery), mother and child had no relevant clinical or laboratory abnormalities. The antibiotics were well tolerated by the mother. Blood cultures from the mother drawn in week 7 after delivery remained negative; the IgM titre was slightly decreased to $18 \mathrm{U}$.

After the identification of Brucella spp., two persons from the delivery room were monitored and had serological follow-up. All serological tests at their first visit and three months later were negative.

\section{Background}

Brucellosis is a zoonosis that occurs worldwide, causing great economic losses and a high number of human infections in endemic regions, such as the Mediterranean, the Middle East including Syria, Iraq, Iran and Saudi Arabia, as well as Africa, Asia and Middle and South America. It is estimated that more than 500,000 people are suffering from brucellosis annually [1]. In contrast, only 22 to 47 cases annually were reported in Germany between 2010 and 2015. Most of these cases were associated with travel to endemic countries surrounding the Mediterranean Sea (Italy, Spain, Turkey). Between January 2015 and June 2016, 60 cases of brucellosis in Germany were reported to the Robert Koch Institute, 14 from the Middle East and North African countries, including four cases from Turkey. This seems to point towards a tendency of increased importations from these regions. Imported brucellosis plays an emergent role in Europe and globally $[2,3]$.

B. melitensis (goats and sheep) is the most important species for human brucellosis, but other species like $B$. abortus (cattle), $B$. suis biovar 1 (swine) and $B$. canis (dogs) can also be associated with human cases. The small Gram-negative coccobacilli are most commonly transmitted to humans through contaminated food, e.g. unpasteurised milk, or by direct contact with infected animals $[4,5]$. They grow intracellularly, e.g. in mononuclear phagocytic cells, cause unspecific clinical manifestations especially in the acute stage, including typically undulant fever, which may last for years if not properly treated. The bacteria can be disseminated to various organs such as liver, spleen, bones and joints, genitourinary tract, skin, lung, heart and central nervous system. Therefore, human brucellosis has a broad variability of clinical signs and can mimic other infectious and non-infectious diseases. The infection is often diagnosed only when focal complications occur. Symptoms in children and teenagers with brucellosis are mostly fever, joint pain and hepatomegaly $[6,7]$. Intrauterine infections and transmission of the pathogen through breastfeeding has been reported, transmission of antibodies from mother to newborn is possible [7].

The laboratory diagnosis is mainly based on classical microbiological methods (but isolation could be cumbersome and is not always successful), on MALDI-TOF MS identification of colonies and on PCR that allows the discrimination of Brucella species [8-13]. In addition, multilocus variable-number tandem repeat analysis and other methods like whole genome sequencing, next generation sequencing and single nucleotide polymorphism analysis allow the generation of molecular epidemiology data that can be helpful in the identification of outbreak-related strains and the geographical relation between isolates $[14,15]$. The detection of IgG and IgM antibodies against Brucella antigens in serum is a reliable tool for diagnosing human brucellosis and classifying the stage of disease $[16,17]$. IgM 
anti-Brucella antibodies indicate acute infection, and a titre increase in paired serum samples indicates an acute or reactivated infection.

\section{Discussion}

The accidental cultivation of Brucella melitensis in blood cultures drawn during post-partum fever demonstrates the complexity of this diagnosis. The anamnestic, clinical and laboratory data of our patient were consistent with a protracted or chronic course of brucellosis activated during pregnancy and/or delivery. However, the exact point in time and place of infection of our patient cannot be determined. As she was working as sheepherder in her home country before coming to Germany, she may have been infected in Syria, but infection along the route of migration is also possible. Prolonged antimicrobial therapy is imperative for achieving cure; monotherapy is associated with a high rate of relapse. In this case, the 12-week regimen based on oral doxycycline $100 \mathrm{mg}$ twice a day in combination with rifampicin $900 \mathrm{mg} /$ day in a single dose was preferred because of its oral application and fewer adverse effects compared to the combination of doxycycline with aminoglycosides (such as streptomycin or gentamicin).

Because of possible transmission either transplacentally or through breastfeeding (during the 11 days until diagnosis), the baby was examined. Antibacterial treatment was not started for the baby because there were no relevant clinical or laboratory abnormalities. Regular examinations, at least every three months over a period of one year, were advised.

Although person-to-person transmission of brucellosis is rare, transmission may occur in contact with contaminated blood and by aerosol-producing diagnostic procedures [18]. For patients suffering from human brucellosis during hospitalisation, standard precautions and contact precautions for those with draining wounds are required. In the case described here, mother and newborn were in a rooming-in unit and under contact precautions because of hygiene regulations for refugees.

Handling of cultures with human pathogenic Brucella spp. requires biosafety level 3 ( $B S L 3$ ) conditions, i.e. consequent work in a class II biologic safety cabinet. However, for primary diagnostic samples, accidental cultivation of Brucella spp. in a routine (BSL2) laboratory cannot be avoided. This entails working without safety cabinets for reading agar plates, performing phenotypical tests, etc. It was estimated that brucellosis represents the most common laboratory-acquired infection in clinical routine laboratories [19-21], and an enhanced safety policy are necessary to prevent laboratory acquisition of Brucella as well as regular training of the laboratory staff to be aware of how to handle and cultivate highly pathogenic bacteria such as Brucella spp. In our case, technicians had regularly been trained to recognise the combination of small faintly stained
Gram-negative coccobacilli ('fine sand'), slow-growing small colonies on Columbia blood agar and the requirement of aerobic conditions with $\mathrm{CO}_{2}$ enrichment, and were aware of the necessary biosafety measures. When Brucella spp. was suspected during reading of the agar plates, handling outside a safety cabinet was immediately stopped. All following steps for identification were performed under a class II biosafety cabinet with adequate precautions; as the risk of infection of laboratory personnel was high, we consider that these measures were effective in preventing an infection.

\section{Lessons learnt}

The clinical microbiological laboratory plays a key role in the diagnosis and management of human brucellosis. It should provide a rapid and exact identification of every Gram-negative rod that is cultivated from blood culture or surgical material to exclude Brucella spp. or other highly pathogenic bacteria. Currently, the most suitable tool for identification of bacteria is MALDITOF MS because it provides rapid, accurate, sensitive and cost-effective identification of human pathogenic bacteria. Attention should be paid using commercially available MALDI-TOF MS systems including standard diagnostic databases to identify Brucella spp. and other highly pathogenic bacteria. The related MALDITOF MS databases do not usually support validated laboratory diagnoses of highly pathogenic bacteria, which should be improved in the future. In addition, when highly pathogenic bacteria such as Brucella spp. are suspected or the results are ambiguous, material should be sent to a reference laboratory for further confirmation and identification at species level. When sending live material, the international dangerous goods regulations for air transportation (International Air Transportation Association (IATA)) [22] and ground transportation (Accord européen relatif au transport international des marchandises Dangereuses par Route (ADR)) [23] need to be considered. Alternatively, for PCR and genome analyses, sending bacterial DNA can be sufficient. Genetic material prepared by an evaluated protocol including safe inactivation of the pathogen can be sent without considering specific shipment regulations.

We can assume that physicians in non-endemic European areas have a poor awareness of imported brucellosis in patients arriving from regions with endemic brucellosis, exemplified in our case by people who have migrated from regions in the Middle East. Although our patient had been in Germany for nine months and in ambulatory care during pregnancy, questions on travel history, animal contacts and consumption of raw animal products or duration of symptoms were not asked $[4,24]$. A connection between hip pain and brucellosis was not made.

\section{Acknowledgements}

We thank Mirko Faber (Robert Koch Institute) for the statistical data on brucellosis in Germany and Silke Becker, Petra 
Lochau, and Anne Barduhn (Robert Koch Institute, ZBS 2) as well as Marina Fiedel and Ingrid Politowski (Labor Berlin, Microbiology) for excellent technical assistance.

\section{Conflict of interest}

None declared.

\section{Authors' contributions}

Roland Grunow and Sonja Swidsinski wrote the manuscript. Dietmar Schlembach, Sabine Jackowski-Dohrmann treated the patient. Sonja Swidsinski, Bettina Eberspächer and Silke Klee, Daniela Jacob performed the initial and confirmatory microbiological tests. Roland Grunow, Sonja Swidsinski, Vera Loenning-Baucke, Daniela Jacob, read and revised the manuscript.

\section{References}

1. Pappas G, Papadimitriou P, Akritidis N, Christou L, Tsianos EV. The new global map of human brucellosis. Lancet Infect Dis. 2006;6(2):91-9. DOI: 10.1016/S1473-3099(06)70382-6 PMID: 16439329

2. Garofolo G, Fasanella A, Di Giannatale E, Platone I, Sacchini L, Persiani T, et al. Cases of human brucellosis in Sweden linked to Middle East and Africa. BMC Res Notes. 2016;9(1):277. DOI: 10.1186/s13104-016-2074-7 PMID: 27188619

3. Norman FF, Monge-Maillo B, Chamorro-Tojeiro S, Pérez-Molina JA, López-Vélez R. Imported brucellosis: A case series and literature review.Travel Med Infect Dis. 2016;14(3):182-99. DOI: 10.1016/j.tmaid.2016.05.005 PMID: 27185403

4. Garcell HG, Garcia EG, Pueyo PV, Martín IR, Arias AV, Alfonso Serrano RN. Outbreaks of brucellosis related to the consumption of unpasteurized camel milk.J Infect Public Health. 2016;9(4):523-7. DOI: 10.1016/j.jiph.2015.12.006 PMID: 26796768

5. Al Dahouk S, Neubauer H, Hensel A, Schöneberg I, Nöckler K, Alpers K, et al. Changing epidemiology of human brucellosis, Germany, 1962-2005. Emerg Infect Dis. 2007;13(12):1895-900. DOI: 10.3201/eid1312.070527 PMID: 18258041

6. Bosilkovski M, Krteva L, Caparoska S, Labacevski N, Petrovski M. Childhood brucellosis: Review of 317 cases. Asian Pac J Trop Med. 2015;8(12):1027-32. DOI: 10.1016/j.apjtm.2015.11.009 PMID: 26706674

7. Cacace ML, Claros EA, Erazu KA, Escobar GI, Lucero NE. Congenital brucellosis in an infant.Vector Borne Zoonotic Dis. 2013;13(7):513-5. DOI: 10.1089/vbz.2012.1165 PMID: 23590322

8. Kim JY, Kang SI, Lee JJ, Lee K, Sung SR, Erdenebaataar J, et al. Differential diagnosis of Brucella abortus by real-time PCR based on a single-nucleotide polymorphisms. J Vet Med Sci. 2016;78(4):557-62. DOI: 10.1292/jvms.15-0541 PMID: 26666176

9. Piranfar V, Sharif M, Hashemi M, Vahdati AR, Mirnejad R. Detection and discrimination of two Brucella species by multiplex real-time PCR and high-resolution melt analysis curve from human blood and comparison of results using RFLP. Iran J Basic Med Sci. 2015;18(9):909-14.PMID: 26523223

10. Hänsel C, Mertens K, Elschner MC, Melzer F. Novel realtime PCR detection assay for Brucella suis.Vet Rec Open. 2015;2(1):e000084. DOI: 10.1136/vetrec0-2014-000084 PMID: 26392898

11. Lasch P, Wahab T, Weil S, Pályi B, Tomaso H, Zange S, et al. Identification of highly pathogenic microorganisms by matrix-assisted laser desorption lonization-time of flight mass spectrometry: Results of an interlaboratory ring trial. J Clin Microbiol. 2015;53(8):2632-40. DOI: 10.1128/JCM.00813-15 PMID: 26063856

12. Karger A, Melzer F, Timke M, Bettin B, Kostrzewa M, Nöckler K, et al. Interlaboratory comparison of intact-cell matrix-assisted laser desorption ionization-time of flight mass spectrometry results for identification and differentiation of Brucella spp. J Clin Microbiol. 2013;51(9):3123-6. DOI: 10.1128/JCM.01720-13 PMID: 23850950

13. Mesureur J, Ranaldi S, Monnin V, Girard V, Arend S, Welker $M$, et al. A Simple and safe protocol for preparing Brucella samples for matrix-assisted laser desorption Ionizationtime of flight mass spectrometry analysis. I Clin Microbiol. 2016;54(2):449-52. DOI: 10.1128/JCM.02730-15 PMID: 26582837
14. Scholz HC, Vergnaud G. Molecular characterisation of Brucella species.Rev Sci Tech. 2013;32(1):149-62. DOI: 10.20506 rst.32.1.2189 PMID: 23837373

15. Garofolo G, Di Giannatale E, De Massis F, Zilli K, Ancora M, Cammà $C$, et al. Investigating genetic diversity of Brucella abortus and Brucella melitensis in Italy with MLVA-16. Infect Genet Evol. 2013;19:59-70. DOI: 10.1016/j.meegid.2013.06.021 PMID: 23831636

16. Al Dahouk S, Sprague LD, Neubauer H. New developments in the diagnostic procedures for zoonotic brucellosis in humans. Rev Sci Tech. 2013;32(1):177-88. DOI: 10.20506/rst.32.1.2204 PMID: 23837375

17. Solís García Del Pozo J, Lorente Ortuño S, Navarro E, Solera J. Detection of IgM antibrucella antibody in the absence of IgGs: a challenge for the clinical interpretation of brucella serology. PLoS Negl Trop Dis. 2014;8(12):e3390. DOI: 10.1371/journal. pntd.0003390 PMID: 25474572

18. Lowe CF, Showler AJ, Perera S, McIntyre S, Qureshi R, Patel SN, et al. Hospital-associated transmission of Brucella melitensis outside the laboratory. Emerg Infect Dis. 2015;21(1):150-2. DOI: 10.3201/eid2101.141247 PMID: 25531198

19. Yagupsky P, Baron EJ. Laboratory exposures to brucellae and implications for bioterrorism. Emerg Infect Dis. 2005;11(8):11805. DOI: 10.3201/eid1108.041197 PMID: 16102304

20. Traxler RM, Lehman MW, Bosserman EA, Guerra MA, Smith TL. A literature review of laboratory-acquired brucellosis.J Clin Microbiol. 2013;51(9):3055-62. DOI: 10.1128/JCM.00135-13 PMID: 23824774

21. Singh K. Laboratory-acquired infections.Clin Infect Dis. 2009;49(1):142-7. DOI: 10.1086/599104 PMID: 19480580

22. Regulations DG. (DGR). International Air Transport Association (IATA); 2016. Available from: http://www.iata.org/publications/ dgr/Pages/manuals.aspx

23. European Agreement concerning the International Carriage of Dangerous Goods by Road. ADR applicable as from 1 January 2015. Geneva: United Nations Economic Commission for Europe (UNECE); 2015. Available from: http://www.unece.org/trans/ danger/publi/adr/adr2015/15contentse.html

24. Rhodes HM, Williams DN, Hansen GT. Invasive human brucellosis infection in travelers to and immigrants from the Horn of Africa related to the consumption of raw camel milk. Travel Med Infect Dis. 2016;14(3):255-60. DOI: 10.1016/j. tmaid.2016.03.013 PMID: 27038818

\section{License and copyright}

This is an open-access article distributed under the terms of the Creative Commons Attribution (CC BY 4.0) Licence. You may share and adapt the material, but must give appropriate credit to the source, provide a link to the licence, and indicate if changes were made.

This article is copyright of the authors, 2016. 